\title{
Purchasing Inventory Models for Deteriorating Items with Quadratic Demand
}

\section{K. Sivashankari}

Mathematics Department, RMK Engineering College, India

Address: RSM Nagar, Kavaraipettai, Gummidipoondi Taluk, Tiruvallur District, Tamil Nadu, India

Corresponding author: vinangi.ck@gmail.com

\section{ARTICLE INFO}

\section{Article history}

Received February 12, 2019

Revised July 30, 2019

Accepted August 12, 2019

Available Online August 31, 2019

\section{Keywords}

Inventory

Deteriorating

Quadratic demand

Lot size

\begin{abstract}
This paper deals with purchasing inventory replenishment policy for deteriorating items, considering the time-dependent quadratic demand and time-dependent backlogging. Two models were formulated and solved. First, it is for deteriorating items with quadratically time-dependent demand for deteriorating items. Second, quadratically time-dependent demand for deteriorating items and shortages. A mathematical model is developed to the fourth-order equation for each model. The optimal production lot size, which minimizes the total cost, is derived. Sensitivity analysis is carried out to demonstrate the effects of changing parameter values on the optimal solution of the system. Numerical examples are taken to illustrate the procedure of finding the optimal inventory cost, cycle time, and optimal lot size. The numerical experiment in this model was coded in Microsoft Visual Basic 6.0.
\end{abstract}

This is an open-access article under the CC-BY-SA license.

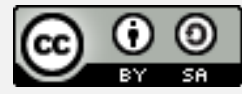

\section{Introduction}

The Classical inventory models assume constant demand in an endless planning horizon [1]. This assumption is valid during the maturation process of the product life cycle and the finite span. The inventory can be improved in other stages of the product life cycle. It is a positive business launch or a decline due to the introduction of new rival goods. However, demand is not always constant in reality, and the market is called timedependent. The main issue of the current paper and inventory model is the timedependent quadratic demand, time-proportional deterioration, and backlog. Most inventory modelers consider time-varying demand. It is known to be linear and exponential in two types of time-dependent demands. Linear time-dependent demand $D=a+b t$ implies a steady increase or decrease in demand according as $\mathrm{b}>0$ (or) $\mathrm{b}<$ 0 . It is unrealistic in the real market. On the other hand, an exponentially time-varying demand $D=D e^{a t}$ is unrealistic because, in real market situations, demand is unlikely to vary at a high rate as exponential. Therefore, the time-dependent quadratic demand of the form $D=a+b t+c t^{2}, \mathrm{a}>0$, seems to be a better representation of time-varying market demand. 
Researchers in inventory problems have carried out several studies. Economic order quantity (EOQ) models have been studied by Harris [1] that presented the famous EOQ formulae. Dave and Patel [2] Considered an EOQ model in which the demand rate is changing linearly with time and Bose, et al. [3] proposed a model of two different inflation rates. The inventory model for deteriorating the items that occur at a fixed rate independent of time was developed by Skouri and Papachristos [4]. Ghosh, et al. [5] developed an inventory model for deteriorating items, a quadratic time-vary demand, and shortages in inventory. Furthermore, Ghosh and Chaudhuri [6] developed an EOQ model over a finite time-horizon for a deteriorating item with a quadratic, timedependent demand, allowing shortages in inventory rate of deterioration are taken to be time-proportional. It is assumed that the shortage occurs in every cycle. a deterministic inventory model when the deterioration rate is time proportional and the demand rate is a function of selling price and holding cost is time-dependent was proposed by Roy [7]. Cheng and Wang [8] implemented an inventory model for deteriorating items with a trapezoidal type demand rate.

Besides, Jaggi and Verma [9] developed a two warehouses inventory model with a linear demand under inflationary conditions. Mandal [10] considered the depletion not only by demand but also by deterioration. An EOQ inventory problem over a finite time for deteriorating items with shortages, where the demand rate is of the ramp-type, was discussed by Roy and Chaudhuri [11]. Cheng, et al. [12] studied an inventory model for time-dependent deteriorating items with trapezoidal type demand and partial backlogging. The two-warehouses inventory model with a partial backorder and Weibull distribution deteriorating was implemented by Kumar, et al. [13]. It is considered inflation and applies the discounted cash flow in problem analysis. Sarkar, et al. [14] proposed an optimal inventory replenishment policy for deteriorating items timequadratic demand and time-dependent partial backlogging. A deterministic inventory model with time-dependent demand and time-varying holding cost was developed by Mishra, et al. [15]. Furthermore, De and Sana [16] studied an economic order quantity model for fuzzy variables with promotional effort and selling price-dependent demand. An order-level inventory system for deteriorating items with the demand rate as a ramp type function of time was implemented by Manna, et al. [17]. Islam, et al. [18] proposed a time-dependent inventory model based on a constant production rate. Kaliraman, et al. [19] proposed a two warehouses inventory model for deteriorating items with exponential demand rate and permissible delay in payment.

In this model, one warehouse is rented, and the other is owned. The rented warehouse is provided with a better facility for the stock than the owned warehouse, but it is charged more. To the best of our knowledge, no research addresses this problem. This model aims to find the best replenishment policies for minimizing the total appropriate inventory cost. Tripathi, et al. [20] Established an inventory model with exponential time-dependent demand and time-dependent deterioration that is allowed by shortages. An inventory model for deteriorating products having demand, which is the selling price function, was proposed by Singh, et al. [21]. In this model, the deteriorating rate is time-varying with the quadratic function of time. They are considered a quadratic function of time. In this paper, two inventory models are developed in which (1) inventory model for deteriorating items, (2) inventory model for shortages. The remaining of the paper is organized as follows: Section 2 presents the assumptions and notations. Section 3 is problem formulation and numerical examples. Finally, the paper summarizes and concludes in section 5. 


\section{Methods}

\subsection{Assumptions}

In this paper, we use assumption is used to formulate the problem such as: (1) Initially, the inventory level is zero; (2) The demand rate is a quadratic function $D=a+b t+c t^{2}$ where a>0, $b \neq 0, c \neq 0$, at time $\mathrm{t}$ and it is a continuous function of time. Here, a, b, and c are constants, and "a" stands for the initial demand "b" and "c" are a positive trend in demand; (3) The holding cost, ordering cost, and shortage cost remain constant over time; (4) The planning horizon is finite; (5) The lead time is zero; and (6) There is no repair or replacement of the deteriorated items.

\subsection{Notations}

$\begin{array}{ll} & \text { Notations are used in this paper such as; } \\ D & : \text { Demand rate in units per unit time } \\ Q^{*} & : \text { Optimal lot size (Unit) } \\ \theta & : \text { Rate of deteriorative } \\ C_{d} & : \text { Deterioration cost per unit }(\$) \\ \mathrm{B} & : \text { Number of shortages in unit } \\ C_{S} & : \text { Shortage cost per unit }(\$) \\ C_{0} & : \text { Ordering cost/order }(\$) \\ C_{h} & : \text { Holding cost per unit/time }(\$) \\ T & : \text { Cycle time } \\ S C & : \text { Setup Cost }(\$) \\ H C & : \text { Holding cost }(\$) \\ D C & : \text { Deterioration cost }(\$) \\ S h C & : \text { Shortage Cost }(\$) \\ T C & : \text { Total cost }(\$) \\ a & : \text { Initial demand } \\ b, c & : \text { Positive trend } \\ I & : \text { Inventory level }\end{array}$

\subsection{Purchasing Inventory Model for Deteriorating Items with Quadratic Demand}

The typical behavior of the inventory model has depicted in Fig. 1. The inventory starts with zero stock at zero time. In most of the inventory models, demand has considered a constant function. Nevertheless, in a realistic situation, demand is always not a constant function. It is varying according to time. Therefore, this model developed a deterministic deteriorating inventory model. The demand is a quadratic function of time, that is $a+b t+c t^{2}$, where $a>0, b \neq 0, c \neq 0$ at time $\mathrm{t}$ and "a" stands for the initial demand, and " $\mathrm{b}$ " is a positive trend in demand, and the deterioration rate is constant.

The following differential equation gives the instantaneous inventory level $\mathrm{I}(\mathrm{t})$.

$$
\frac{d}{d t} I(t)+\theta I(t)=-\left(a+b t+c t^{2}\right) ; 0<t<T
$$


with the boundary conditions are

$I(0)=Q ; I(T)=0$

The solution of equation (1) is shown in equation (3).

$\mathrm{I}(\mathrm{t})=\left(\frac{a+b T+c T^{2}}{\theta}-\frac{b+2 c t}{\theta^{2}}+\frac{2 c}{\theta^{3}}\right) e^{\theta(T-t)}-\frac{a+b t+c t^{2}}{\theta}+\frac{b+2 c t}{\theta^{2}}-\frac{2 c}{\theta^{3}}$

The total cost includes the sum of the cost of installation, the cost of holding, and the deterioration cost. Setup cost, holding cost, deteriorating cost, and total cost, respectively, are shown in equations (4), (5), (6), and (7).

$$
\begin{aligned}
S C & =\frac{C_{0}}{T} \\
H C & =\frac{C_{h}}{T}\left[\int_{o}^{T} I(t) d t\right] \\
& =\frac{C_{h}}{T} \int_{o}^{T}\left[\left(\frac{a+b T+c T^{2}}{\theta}-\frac{b+2 c T}{\theta^{2}}+\frac{2 c}{\theta^{3}}\right) e^{\theta(T-t)}-\frac{a+b t+c t^{2}}{\theta}+\frac{b+2 c t}{\theta^{2}}-\frac{2 c}{\theta^{3}}\right] d t
\end{aligned}
$$

The $\theta$ is discarded since it is minimal, so.

$$
\begin{aligned}
& H C=\frac{C_{h}}{T}\left[\frac{a T^{2}}{2}+\frac{b T^{3}}{2}+\frac{c T^{4}}{2}\right]=\frac{C_{h}}{2}\left[a T+b T^{2}+c T^{3}\right] \\
& D C=\frac{\theta C_{d}}{T}\left[\int_{o}^{T} I(t) d t\right]=\frac{\theta C_{d}}{2}\left(a+b T+c T^{2}\right) T
\end{aligned}
$$

Therefore,

$T C=\frac{C_{0}}{T}+\frac{\left(C_{h}+\theta C_{d}\right)\left(a+b T+c T^{2}\right) T}{2}$

To solve TC optimal, it can be easily shown that TC (T) is a convex function in $\mathrm{T}$. Hence, an optimal cycle time T can be calculated from:

$\frac{d}{d T} T C(T)=0$ and $\frac{d^{2}}{d T^{2}} T C(T)>0$

the total cost equation (7) is derivatized to $\mathrm{T}$, then 


$$
\begin{aligned}
& \frac{d}{d T}(T C)=\frac{-C_{0}}{T^{2}}+\frac{\left(C_{h}+\theta C_{d}\right)\left(a+2 b T+3 c T^{2}\right)}{2}=0 \\
& \frac{\left(C_{h}+\theta C_{d}\right)\left(a+2 b T+3 c T^{2}\right)}{2}=\frac{C_{0}}{T^{2}}
\end{aligned}
$$

and $\frac{d^{2}}{d T^{2}}(T C)=\frac{2 C_{0}}{T^{3}}+\frac{\left(C_{h}+\theta C_{d}\right)(a+2 b+6 c T)}{2}>0$

$$
3 c T^{4}+2 b T^{3}+a T^{2}-\frac{2 C_{0}}{C_{h}+\theta C_{d}}=0
$$

Equation (8) is the equation for the optimum solution for the total cost. It should be noted that When $\mathrm{b}=0, \mathrm{c}=0$, and $\mathrm{a}=\mathrm{D}$, then $T=\sqrt{\frac{2 C_{0}}{D\left(C_{h}+\theta C_{d}\right)}}$ which is the standard model.

\subsection{Purchasing Inventory Model for Deteriorating Items with Quadratic Demand and Shortage}

The typical behavior of the inventory model is depicted in Fig. 2. The inventory starts with zero stock at zero time. The shortage $T_{1}$ is to accumulate at the early stage of the inventory cycle. Therefore, this model developed the deteriorating inventory model. The demand is a linear function of time. That is $D=a+b t+c t^{2}$, where $a>0, b \neq 0, c \neq 0$ at time $\mathrm{t}$ and "a" stands for the initial demand and "b" and "c" are a positive trend in demand. Therefore, the deterioration rate is constant.

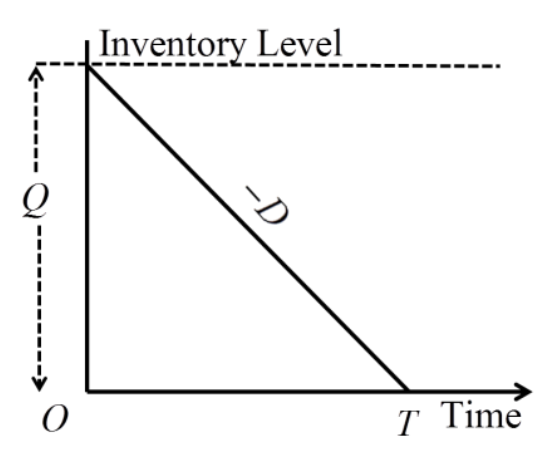

Fig. 1. EOQ model with deteriorating items

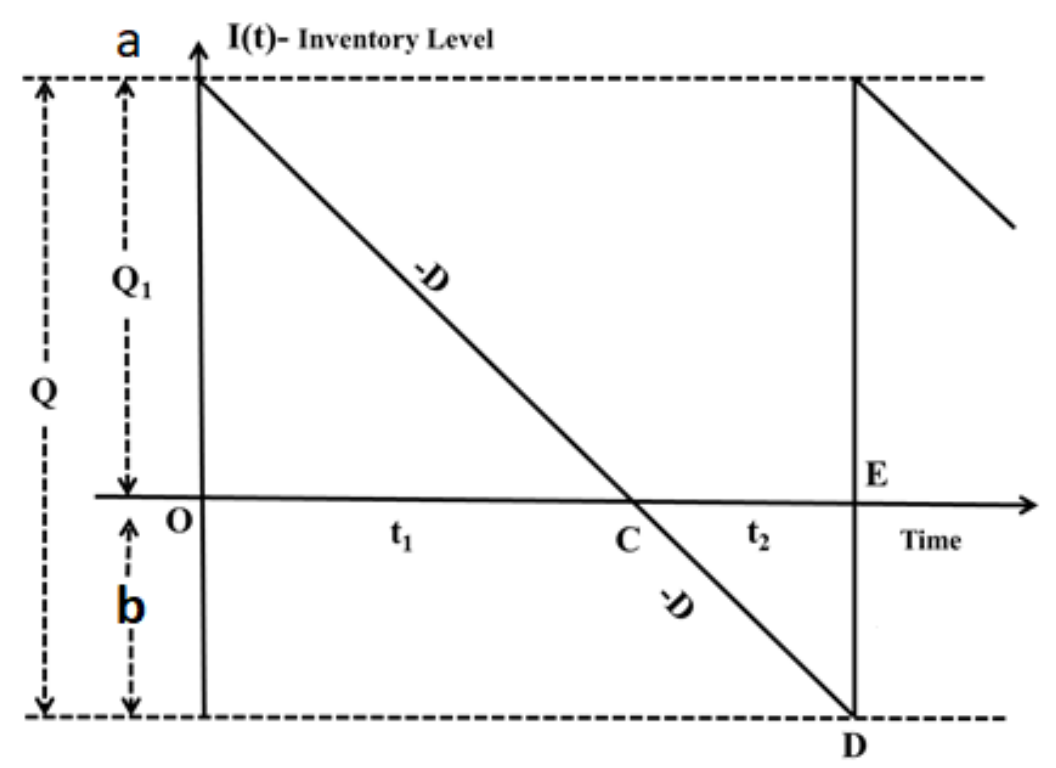

Fig. 2. EOQ Model With Shortages

The following derivative equations give the instantaneous inventory level $\mathrm{I}(\mathrm{t})$ 


$$
\frac{d}{d t} I(t)+\theta I(t)=-\left(a+b t+c t^{2}\right) ; 0<t<T_{1}
$$

The instantaneous shortage $\mathrm{I}(\mathrm{t})$ during the period of shortage is given by the derivative of equation (10).

$$
\frac{d}{d t} I(t)=-\left(a+b t+c t^{2}\right) ; T_{1}<t<T
$$

with the boundary conditions are

$$
I\left(T_{1}\right)=0 \text { and } I(T)=B, I(0)=Q_{1}
$$

The solution of equation (9) is

$$
I(t)=\left(\frac{a+b T_{1}+c T_{1}^{2}}{\theta}-\frac{b+2 c T_{1}}{\theta^{2}}+\frac{2 c}{\theta^{3}}\right) e^{\theta\left(T_{1}-t\right)}-\frac{a+b t+c t^{2}}{\theta}+\frac{b+2 c t}{\theta^{2}}-\frac{2 c}{\theta^{3}}
$$

The solution of the equation (10) is

$$
I(t)=a\left(t-T_{1}\right)+\frac{b}{2}\left(t^{2}-T_{1}^{2}\right)+\frac{c}{3}\left(t^{3}-T_{1}^{3}\right)
$$

From equation (9) and boundary conditions

$$
I(0)=Q_{1} \Rightarrow Q_{1}=\left(\frac{a+b T_{1}+c T_{1}^{2}}{\theta}-\frac{b+2 c T_{1}}{\theta^{2}}+\frac{2 c}{\theta^{3}}\right) e^{\theta T_{1}}-\frac{a}{\theta}+\frac{b}{\theta^{2}}-\frac{2 c}{\theta^{3}}
$$

Total cost comprised the sum of the setup cost, holding cost, deteriorating cost, shortage cost. Setup cost, holding cost, deteriorating cost, Shortage cost, and total cost, respectively, are shown in equations (14), (15), (16), (17), and (18).

$$
\begin{aligned}
S C & =\frac{C_{0}}{T} \\
H C & =\frac{C_{h}}{T}\left[\int_{o}^{T_{1}} I(t) d t\right] \\
& =\frac{C_{h}}{T} \int_{o}^{T_{1}}\left[\left(\frac{a+b T_{1}+c T_{1}^{2}}{\theta}-\frac{b+2 c T_{1}}{\theta^{2}}+\frac{2 c}{\theta^{3}}\right) e^{\theta\left(T_{1}-t\right)}-\frac{a+b t+c t^{2}}{\theta}+\frac{b+2 c t}{\theta^{2}}-\frac{2 c}{\theta^{3}}\right] d t
\end{aligned}
$$




$$
H C=\frac{C_{h}}{T}\left[\begin{array}{l}
\frac{-1}{\theta}\left(\frac{a+b T_{1}+c T_{1}^{2}}{\theta}-\frac{b+2 c T_{1}}{\theta^{2}}+\frac{2 c}{\theta^{3}}\right)-\frac{a T_{1}}{\theta}-\frac{b T_{1}^{2}}{2 \theta}-\frac{c T_{1}^{3}}{3 \theta} \\
+\frac{b T_{1}}{\theta^{2}}+\frac{c T_{1}^{2}}{\theta^{2}}-\frac{2 c T_{1}}{\theta^{3}}+\frac{1}{\theta}\left(\frac{a+b T_{1}+c T_{1}^{2}}{\theta}-\frac{b+2 c T_{1}}{\theta^{2}}+\frac{2 c}{\theta^{3}}\right) e^{\theta T_{1}}
\end{array}\right]
$$

The $\theta$ is discarded since it is minimal, so.

$$
\begin{aligned}
H C & =\frac{C_{h}}{T}\left[\frac{a T_{1}^{2}}{2}+\frac{b T_{1}^{3}}{2}+\frac{c T_{1}^{4}}{2}\right]=\frac{C_{h}}{2 T}\left[a T_{1}^{2}+b T_{1}^{3}+c T_{1}^{4}\right] \\
D C & =\frac{\theta C_{d}}{T}\left[\int_{o}^{T_{1}} I(t) d t\right]=\frac{\theta C_{d}}{2 T}\left[a T_{1}^{2}+b T_{1}^{3}\right] \\
S h C & =\frac{C_{S}}{T} \int_{T_{1}}^{T} I(t) d t \\
& =\frac{C_{S}}{T} \int_{T_{1}}^{T}\left[a\left(t-T_{1}\right)+\frac{b}{2}\left(t^{2}-T_{1}^{2}\right)+\frac{c}{3}\left(t^{3}-T_{1}^{3}\right)\right] d t \\
& =\frac{C_{S}}{T}\left[\frac{a}{2}\left(T-T_{1}\right)^{2}+\frac{b}{6}\left(T^{3}-3 T_{1}^{2}+2 T_{1}^{3}\right)+\frac{c}{12}\left(T^{4}-4 T_{1}^{3} T+3 T_{1}^{4}\right)\right]
\end{aligned}
$$

$\mathrm{TC}=\left[\begin{array}{l}\frac{C_{0}}{T}+\frac{C_{h}+\theta C_{d}}{2 T}\left(a T_{1}^{2}+b T_{1}^{3}+c T_{1}^{4}\right) \\ +\frac{C_{S}}{T}\left[\frac{a}{2}\left(T-T_{1}\right)^{2}+\frac{b}{6}\left(T^{3}-3 T_{1}^{2}+2 T_{1}^{3}\right)+\frac{c}{12}\left(T^{4}-4 T_{1}^{3} T+3 T_{1}^{4}\right)\right.\end{array}\right]$

$\mathrm{TC}(\mathrm{T})$ is a convex function in $\mathrm{T}$. Hence; an optimal cycle time $\mathrm{T}$ can be calculated from

$$
\begin{gathered}
\frac{\partial}{\partial T_{1}} T C\left(T_{1}\right)=0 \text { and } \frac{\partial^{2}}{\partial T_{1}^{2}} T C\left(T_{1}\right)>0 \\
\frac{\partial}{\partial T} T C(T)=0 \text { and } \frac{\partial^{2}}{\partial T^{2}} T C(T)>0
\end{gathered}
$$

Partially derivative the total cost equation (18) to $T_{1}$, then 


$$
\frac{\partial}{\partial T_{1}}(T C)=\left[\begin{array}{l}
\frac{\left(C_{h}+\theta C_{d}\right)\left(2 a T_{1}+3 b T_{1}^{2}+4 c T_{1}^{3}\right)}{2 T} \\
+\frac{C_{S}}{T}\left[\frac{2 a}{2}\left(T-T_{1}\right)(-1)+\frac{b}{6}\left(-6 T T_{1}+6 T_{1}^{2}\right)+\frac{c}{12}\left(-12 T_{1}^{2} T+12 T_{1}^{3}\right)\right]
\end{array}\right]=0
$$

Therefore, $T_{1}=\frac{a C_{S} T}{a\left(C_{h}+\theta C_{d}+C_{S}\right)-b C_{S} T}$

Partially derivative of the total cost equation (18) to $\mathrm{T}$ is

$$
\begin{aligned}
& \frac{\partial}{\partial T}(T C)=\left[\begin{array}{l}
\frac{-C_{0}}{T^{2}}-\frac{\left(C_{h}+\theta C_{d}\right)\left(a T_{1}^{2}+b T_{1}^{3}+C T_{1}^{4}\right)}{2 T^{2}} \\
+\frac{C_{S}}{2 T^{2}}\left[\begin{array}{l}
a\left(T-T_{1}\right)-\left(T+T_{1}\right)^{2}+\frac{b}{3}\left(3 T^{2}-3 T_{1}^{2}\right)-\left(T^{3}-3 T_{1}^{2} T+2 T_{1}^{3}\right) \\
+\frac{c}{12}\left\{\frac{T\left(4 T^{4}+4 T_{1}^{3}\right)-\left(T^{4}-4 T T_{1}^{3}+3 T_{1}^{4}\right)}{T^{2}}\right\}
\end{array}\right]=0 \\
{\left[\begin{array}{l}
-\left(C_{h}+\theta C_{d}\right)\left(a T_{1}^{2}+b T_{1}^{3}+c T_{1}^{4}\right)+a C_{S}\left(T^{2}-T_{1}^{2}\right) \\
+b C_{S}\left(\frac{2 T^{3}-2 T_{1}^{3}}{3}\right)+C_{S} C \frac{\left(3 T^{4}-3 T_{1}^{4}\right)}{6}
\end{array}\right]=2 C_{0}}
\end{array}\right]=0
\end{aligned}
$$

and $\frac{\partial^{2}}{\partial T^{2}}(T C)=\frac{2 C_{0}}{T^{3}}+\frac{\left(C_{h}+\theta C_{d}\right) a}{2}>0$

On simplification,

$$
\begin{aligned}
& {\left[\frac{3 C C_{S}\left(\left(C_{h}+\theta C_{d}+C_{S}\right)^{4}-C_{S}^{4}\right)-6 C\left(C_{h}+\theta C_{d}\right) C_{S}^{4}}{\left(C_{h}+\theta C_{d}+C_{S}\right)^{4}}\right] T^{4}} \\
& +\left[\frac{4 b C_{S}\left(\left(C_{h}+\theta C_{d}+C_{S}\right)^{3}-C_{S}^{3}\right)-6 b\left(C_{h}+\theta C_{d}\right) C_{S}^{3}}{\left(C_{h}+\theta C_{d}+C_{S}\right)^{3}}\right] T^{3}+\left[\frac{6 a C_{S}\left(C_{h}+\theta C_{d}\right)}{C_{h}+\theta C_{d}+C_{S}}\right] T^{2}-12 C_{0}=0
\end{aligned}
$$

It should be noted that when $\mathrm{b}=0$ and $\mathrm{a}=\mathrm{D}$, then $T=\sqrt{\frac{2 C_{0}\left(C_{h}+\theta C_{d}+C_{S}\right)}{D C_{S}\left(C_{h}+\theta C_{d}\right)}}$ Which is the standard model.

\subsection{Numerical Experiment}

In the model for deteriorating items with quadratic demand, we used $\mathrm{D}=4500$ unit, $C_{0}=100 \$, C_{h}=10 \$, \theta=0.01 ; C_{d}=100 \$$, a $=4250, \mathrm{~b}=3880$, and $\mathrm{c}=2700$. On the other hand, researchers employed $\mathrm{D}=4500$ unit, $C_{0}=100 \$, C_{h}=10 \$, \theta=0.01 \$$, 
$C_{d}=100 \$, C_{s}=10 \$, \mathrm{a}=4200, \mathrm{~b}=3000$, and $\mathrm{c}=2700$ on model for quadratic demand with shortage. In the sensitivity test of the Rate of deteriorating items toward the total cost, this study used ten variations of the deteriorating rate from 0.01 to 0.10 , and both models performed this test. Sensitivity analysis was also carried out on ordering cost, holding cost, deterioration cost, shortage cost, initial demand (a), and positive trend (b,c). During the experiment, 5 parameter variations were used to determine its effect on inventory. To simplify the experiment, numerical experiments in this model were coded in Microsoft Visual Basic 6.0.

\section{Results and Discussion}

\subsection{Model for Deteriorating Items with Quadratic Demand}

Result from numerical experiment show that the optimal solution is $\mathrm{T}=0.0618$, $\mathrm{Q}^{*}=278.10$, Setup cost $=1618.69 \$$, Holding cost $=1390.54 \$$, Deteriorating cost $=$ $139.05 \$$, and Total cost $=3147.70 \$$. Furthermore, Table 1 shows the Influence variation of the rate of deteriorating items toward the total cost. It is concluded that The greater the rate of deteriorating, the increases the Setup cost, Deteriorating cost, and Total cost. Conversely, the greater the rate of deteriorating, the lowering T, Q, and holding cost.

\begin{tabular}{ccccccc}
\multicolumn{6}{c}{ Table } & \multicolumn{6}{c}{ Influence variation of rate of deteriorating items toward the total cost } \\
$\theta$ & T & Q & $\begin{array}{c}\text { Setup } \\
\text { cost }\end{array}$ & $\begin{array}{c}\text { Holding } \\
\text { cost }\end{array}$ & $\begin{array}{c}\text { Deteriorating } \\
\text { cost }\end{array}$ & Total cost \\
\hline 0.01 & 0.0618 & 278.10 & 1618.10 & 1390.54 & 139.05 & 3147.70 \\
0.02 & 0.0592 & 266.78 & 1686.76 & 1331.26 & 266.25 & 3284.28 \\
0.03 & 0.0571 & 256.84 & 1752.04 & 1278.99 & 383.70 & 3414.74 \\
0.04 & 0.0551 & 247.95 & 1814.85 & 1232.43 & 492.97 & 3540.27 \\
0.05 & 0.0533 & 240.01 & 1874.89 & 1190.64 & 595.32 & 3660.84 \\
0.06 & 0.0517 & 232.74 & 1933.50 & 1152.81 & 691.68 & 3777.99 \\
0.07 & 0.0502 & 226.10 & 1990.30 & 1118.36 & 782.86 & 3891.52 \\
0.08 & 0.0489 & 220.00 & 2045.45 & 1086.84 & 869.47 & 4001.76 \\
0.09 & 0.0476 & 214.38 & 2099.08 & 1057.83 & 952.05 & 4108.97 \\
0.10 & 0.0465 & 209.17 & 2151.32 & 1031.03 & 1031.03 & 4213.40
\end{tabular}

Table 2 shows the effect of demand and cost parameters on optimal values toward $\mathrm{T}$, Q, setup cost, holding cost, deteriorating cost, shortage cost, and total cost. The following influences can be obtained from sensitivity analysis based on Table 2. The finding of sensitivity analysis is as follows 1) Increasing the setup and deteriorating cost raise optimum quantity, cycle time, setup cost, holding cost, deteriorating cost, and total cost increases. These results show that there is a positive relationship between them. 2) Increasing the holding cost also raise the setup cost, holding cost, Deteriorating cost, and total cost. There is a positive relationship between them, but the optimal cycle time and the optimal lot size decreases. Therefore, there is a negative relationship between cycle time and an optimal lot size toward holding costs. Demand parameters a, b, and c also affect the optimal quantity, cycle time, setup cost, holding cost, deteriorating cost, and total cost. When a, b, and c increase, it will increase the setup cost, holding cost, deteriorating cost, and total cost. However, the optimal quantity, cycle time decreases. 
Table 2. Effect of Demand and cost parameters on optimal values

\begin{tabular}{|c|c|c|c|c|c|c|c|}
\hline \multirow{2}{*}{\multicolumn{2}{|c|}{ Parameters }} & \multicolumn{6}{|c|}{ Optimum values } \\
\hline & & $\mathrm{T}$ & $\mathrm{Q}$ & $\mathrm{SC}$ & $\mathrm{HC}$ & $\mathrm{DC}$ & $\mathrm{TC}$ \\
\hline \multirow{5}{*}{$C_{0}$} & 80 & 0.0556 & 250.17 & 1439.04 & 1243.62 & 124.36 & 2807.02 \\
\hline & 90 & 0.0588 & 264.56 & 1530.83 & 1319.12 & 131.91 & 2981.86 \\
\hline & 100 & 0.0618 & 278.10 & 1618.10 & 1390.54 & 139.05 & 3147.70 \\
\hline & 110 & 0.0646 & 290.91 & 1701.54 & 1458.48 & 145.85 & 3305.87 \\
\hline & 120 & 0.0673 & 303.09 & 1781.63 & 1523.41 & 152.34 & 3457.38 \\
\hline \multirow{5}{*}{$C_{h}$} & 8 & 0.0679 & 305.72 & 1471.92 & 1229.97 & 153.75 & 2855.64 \\
\hline & 9 & 0.0646 & 290.91 & 1546.85 & 1312.63 & 145.85 & 3005.33 \\
\hline & 10 & 0.0618 & 278.10 & 1618.10 & 1390.54 & 139.05 & 3147.70 \\
\hline & 11 & 0.0593 & 266.87 & 1686.18 & 1464.42 & 133.13 & 3283.73 \\
\hline & 12 & 0.0571 & 256.93 & 1751.47 & 1534.82 & 127.90 & 3414.19 \\
\hline \multirow{5}{*}{$C_{d}$} & 80 & 0.0623 & 280.53 & 1604.13 & 1403.37 & 112.27 & 3119.77 \\
\hline & 90 & 0.0621 & 279.31 & 1611.13 & 1396.91 & 125.72 & 3133.77 \\
\hline & 100 & 0.0618 & 278.10 & 1618.10 & 1390.54 & 139.05 & 3147.70 \\
\hline & 110 & 0.0615 & 276.91 & 1625.05 & 1384.26 & 152.27 & 3161.58 \\
\hline & 120 & 0.0612 & 275.74 & 1631.96 & 1378.06 & 165.36 & 3175.39 \\
\hline \multirow{5}{*}{$\mathrm{a}$} & 4050 & 0.0631 & 283.79 & 1585.68 & 1357.60 & 135.76 & 3079.03 \\
\hline & 4150 & 0.0624 & 280.90 & 1601.96 & 1374.16 & 137.42 & 3113.54 \\
\hline & 4250 & 0.0618 & 278.10 & 1618.10 & 1390.54 & 139.05 & 3147.70 \\
\hline & 4350 & 0.0612 & 275.38 & 1634.12 & 1406.73 & 140.67 & 3181.53 \\
\hline & 4450 & 0.0606 & 272.72 & 1650.01 & 1422.74 & 142.27 & 3215.02 \\
\hline \multirow{5}{*}{$\mathrm{b}$} & 3680 & 0.0619 & 278.79 & 1614.12 & 1390.34 & 139.03 & 3143.49 \\
\hline & 3780 & 0.0618 & 278.44 & 1616.12 & 1390.44 & 139.04 & 3145.60 \\
\hline & 3880 & 0.0618 & 278.10 & 1618.10 & 1390.54 & 139.05 & 3147.70 \\
\hline & 3980 & 0.0617 & 277.76 & 1620.09 & 1390.64 & 139.06 & 3149.80 \\
\hline & 4080 & 0.0616 & 277.42 & 1622.07 & 1390.75 & 139.07 & 3151.89 \\
\hline \multirow{5}{*}{$\mathrm{c}$} & 2500 & 0.0618 & 278.16 & 1617.74 & 1390.64 & 139.06 & 3147.44 \\
\hline & 2600 & 0.0618 & 278.13 & 1617.92 & 1390.59 & 139.06 & 3147.57 \\
\hline & 2700 & 0.0618 & 278.10 & 1618.10 & 1390.54 & 139.05 & 3147.70 \\
\hline & 2800 & 0.0617 & 278.07 & 1618.29 & 1390.49 & 139.04 & 3147.83 \\
\hline & 2900 & 0.0617 & 278.03 & 1618.47 & 1390.44 & 139.04 & 3147.96 \\
\hline
\end{tabular}

\subsection{Model for Deteriorating Items with Quadratic Demand and Shortage}

In the trial model for deteriorating items with quadratic demand and shortage, the results show $T^{4}+1.2658 T^{3}+1.9506 T^{2}-1.7732=0$. Therefore, the optimal value is $\mathrm{T}=$ $0.0924, T_{1}=0.0454, \quad \mathrm{Q}=415.88$, Setup cost $=1082.03$, Holding cost $=484.97$, Deteriorating cost $=48.50$, Shortage cost $=524.68$, Total cost $=2140.17$. sensitivity analysis variation of the Rate of deteriorating items is shown in Table 3. The study considers deteriorating items on cycle time, optimum quantity, set-up costs, holding costs, deteriorating costs, shortage costs, and total costs. It is concluded that increasing the rate of deterioration of the item enhances the set-up cost, the deterioration costs, shortage cost, and the total cost. These show that there is a positive relationship between them. However, when the rate of deterioration increases, then the cycle time, the optimum quantity, and the holding cost decreases. It shows that there is a negative relationship between them. 
Table 3. Variation of Rate of deteriorating items with inventory and total cost

\begin{tabular}{llllllllll}
$\theta$ & $\mathrm{T}$ & $\mathrm{Q}$ & $T_{1}$ & $Q_{1}$ & $\mathrm{SC}$ & $\mathrm{HC}$ & $\mathrm{DC}$ & $\mathrm{ShC}$ & $\mathrm{TC}$ \\
\hline 0.01 & 0.0924 & 415,88 & 0.0454 & 193.98 & 1082.03 & 484.97 & 48.50 & 524.68 & 2140.17 \\
0.02 & 0.0906 & 407.91 & 0.0424 & 181.08 & 1103.18 & 430.66 & 86.13 & 561.82 & 2181.79 \\
0.03 & 0.0891 & 401.03 & 0.0398 & 169.85 & 1122.11 & 385.23 & 115.57 & 596.19 & 2219.11 \\
0.04 & 0.0878 & 395.02 & 0.0376 & 159.98 & 1139.17 & 346.80 & 138.72 & 628.08 & 2252.77 \\
0.05 & 0.0866 & 389.74 & 0.0355 & 151.22 & 1154.62 & 313.97 & 156.98 & 657.73 & 2283.31 \\
0.06 & 0.0856 & 385.05 & 0.0337 & 143.40 & 1168.68 & 285.68 & 171.41 & 685.37 & 2311.14 \\
0.07 & 0.0846 & 380.86 & 0.0321 & 136.37 & 1181.54 & 261.11 & 182.78 & 711.18 & 2336.01 \\
0.08 & 0.0838 & 377.09 & 0.0306 & 130.01 & 1193.34 & 239.63 & 191.71 & 735.34 & 2360.02 \\
0.09 & 0.0830 & 373.69 & 0.0292 & 124.25 & 1204.21 & 220.74 & 198.66 & 757.99 & 2381.61 \\
0.10 & 0.0823 & 370.59 & 0.0280 & 118.95 & 1214.27 & 204.02 & 204.02 & 779.27 & 2401.58 \\
\hline
\end{tabular}

Table 4. Effect of Demand and cost parameters on optimal values

\begin{tabular}{|c|c|c|c|c|c|c|c|c|c|c|}
\hline \multicolumn{2}{|c|}{ Parameters } & $\mathrm{T}$ & $\mathrm{Q}$ & $T_{1}$ & $Q_{1}$ & $\mathrm{SC}$ & $\mathrm{HC}$ & $\mathrm{DC}$ & $\mathrm{ShC}$ & TC \\
\hline \multirow{5}{*}{$C_{o}$} & 80 & 0.0829 & 73.21 & 0.0406 & 173.19 & 964.61 & 430.77 & 43.08 & 471.59 & 1910.05 \\
\hline & 90 & 0.0878 & 395.17 & 0.0431 & 183.87 & 1024.86 & 458.53 & 45.85 & 498.94 & 2028.19 \\
\hline & 100 & 0.0924 & 415,88 & 0.0454 & 193.98 & 1082.03 & 484.97 & 48.50 & 524.68 & 2140.17 \\
\hline & 110 & 0.0968 & 435.52 & 0.0476 & 203.61 & 1136.58 & 510.27 & 51.03 & 549.04 & 2246.92 \\
\hline & 120 & 0.1009 & 454.22 & 0.0498 & 212.82 & 1188.85 & 534.59 & 53.46 & 572.22 & 2349.11 \\
\hline \multirow{5}{*}{$C_{h}$} & 8 & 0.0970 & 436.36 & 0.0530 & 226.73 & 1031.24 & 505.33 & 63.17 & 440.82 & 2040.57 \\
\hline & 9 & 0.0945 & 425.23 & 0.0489 & 209.01 & & 495.67 & 55.07 & .47 & 2093.45 \\
\hline & 10 & 0.0924 & 415,88 & 0.0454 & 193.98 & 1082.03 & 484.97 & 48.50 & 524.68 & 2140.17 \\
\hline & 11 & 0.0906 & 407.91 & 0.0424 & 181.04 & 1103.18 & 473.72 & 43.07 & 561.81 & 2181.79 \\
\hline & 12 & 0.0891 & 401.03 & 0.0398 & 169.78 & & 462.28 & 38.52 & & 9.11 \\
\hline \multirow{5}{*}{$C_{d}$} & 80 & & & 0.0461 & 196.80 & & & & & \\
\hline & 90 & & & 0.0 & 195.38 & & & & & \\
\hline & 100 & 24 & 415 & 0.0454 & 193.98 & & & 48.50 & & 0.17 \\
\hline & 110 & & 415.03 & 0.0451 & 192.60 & & 479.07 & 52.70 & & 2144.55 \\
\hline & 120 & & & 0.0448 & 191.24 & & & & & \\
\hline \multirow{5}{*}{$C_{S}$} & 8 & & & 0.04 & 181 & & & & & \\
\hline & 9 & & & 0.0 & 181.63 & & & & & \\
\hline & 10 & 0.0924 & 41 & 0.0454 & 193.98 & & 97 & 48 & & 2140.17 \\
\hline & 11 & 02 & 6 & 0.0466 & 199.11 & & 35 & 52 & & .37 \\
\hline & 12 & & & 0.0 & 203.70 & & & & & \\
\hline \multirow{5}{*}{$\mathrm{a}$} & & & & 0.0 & 189.56 & & & & & \\
\hline & 41 & 4 & 4 & 0.0 & 191.78 & & & & & \\
\hline & 420 & 0.0924 & 88 & 0.0454 & 193.98 & & 97 & 48 & 68 & 21 \\
\hline & 430 & 14 & 411.45 & 0.0449 & 196.15 & & 489.58 & 48 & 75 & 2163.99 \\
\hline & 440 & 05 & 407.14 & 0.0444 & 198.31 & & 17 & 49 & 72 & 2187.56 \\
\hline \multirow{5}{*}{ b } & 28 & & 24 & 0.0454 & 193.72 & & 482.79 & & 33 & 7.46 \\
\hline & 2900 & 0.0925 & 416.26 & 0.0454 & 193.85 & 10 & 483.88 & 48 & 525.51 & 2138.82 \\
\hline & 3000 & 0.0924 & 415,88 & 0.0454 & 193.98 & 1082.03 & 484.97 & 48.50 & 524.68 & 2140.17 \\
\hline & 3100 & 0.0923 & 415.51 & 0.0454 & 194.11 & 108 & 486.06 & 48.61 & 523.86 & 2141.53 \\
\hline & 320 & 0.0922 & 415.13 & 0.0454 & 194.24 & 99 & 487.15 & 48.71 & 523.03 & 2142.89 \\
\hline \multirow{5}{*}{$\mathrm{c}$} & 250 & 0.0924 & 50 & 0.0454 & 194.01 & 108 & 485.00 & 48 & 524.66 & 2140.03 \\
\hline & 260 & 0.0924 & 415.91 & 0.0454 & 193.99 & 108 & 484.98 & 48.49 & 524.67 & 2140.10 \\
\hline & 2700 & 0.0924 & 41588 & 0.0454 & 193.98 & 1082.03 & 484.97 & 48.50 & 524.68 & 2140.17 \\
\hline & & & & 0.0454 & 193.96 & 1082.11 & 484.95 & 48.49 & 524.69 & 2140.24 \\
\hline & 2900 & 0.0924 & 415.82 & 0.0454 & 193.95 & 1082.19 & 484.93 & 48.49 & 524.70 & 2140.31 \\
\hline
\end{tabular}


The effect of Demand and cost parameters on optimal values can be shown in Table 4. The experimental findings are as follows 1) increasing setup cost per unit can raise optimum quantity, cycle time, setup cost, holding cost, deteriorating cost, shortage cost, and total cost increases. Therefore, there is a positive relationship between them. 2) increasing in holding cost per unit time enhance the setup cost, holding cost, shortage cost, and total cost. There is a positive relationship between them, but optimal cycle time, optimal lot size, and deteriorating cost decrease. Therefore, there is a negative relationship between holding cost per unit time toward cycle time, lot size, and deteriorating cost. 3) increasing deteriorating cost per unit time enhance the setup cost, deteriorating cost, shortage cost, and total cost. However, it decreases cycle time, lot size, and holding cost. 4) Raising the shortage cost decreases the optimal cycle time, optimal lot size, and shortage cost. However, the replacement time, maximum inventory, setup cost, holding cost, and total cost increase. Other parameters "a", "b", and "c" can be observed from Table 4.

\section{Conclusion}

This paper deals with purchasing inventory replenishment policy for deteriorating items. This model considering the time-dependent quadratic demand. Two models were formulated and solved for deteriorating items with (1) quadratically timedependent demand for deteriorating items and (2) quadratically time-dependent demand for deteriorating items and shortages. The sensitivity analysis also was presented in both models. The proposed model can assist the manufacturer and retailer in determining the optimum quantity, cycle time, and overall inventory cost. This research can be extended as follows: (1) Most of today's production systems are multi-stage systems. In a multi-stage system, defective items and scrap can be produced in each stage. The defectives and scrap for a multi-stage system can be different stages. (2) Inspection costs can be included in developing future models. (3) The demand for a product may decrease with time due to introducing a new product, which is either technically superior or more attractive and cheaper than the old one. On the other hand, the demand for new products will increase. Thus, the demand rate can be varied with time, so the variable demand rate can be used to develop the model.

\section{References}

[1] F. W. Harris, "How many parts to make at once," Operation Research, vol. 38, pp. 947-950, 1990. https://doi.org/10.1287/opre.38.6.947.

[2] U. Dave and L. Patel, "(T, S i) policy inventory model for deteriorating items with time proportional demand," Journal of the Operational Research Society, vol. 32, pp. 137-142, 1981. https://doi.org/10.1057/jors.1981.27.

[3] S. Bose, A. Goswami, and K. Chaudhuri, "An EOQ model for deteriorating items with linear time-dependent demand rate and shortages under inflation and time discounting," Journal of the Operational Research Society, vol. 46, pp. 771-782, 1995. https://doi.org/10.1057/jors.1995.107.

[4] K. Skouri and S. Papachristos, "A continuous review inventory model, with deteriorating items, time-varying demand, linear replenishment cost, partially time-varying backlogging," Applied Mathematical Modelling, vol. 26, pp. 603-617, 2002. https://doi.org/10.1016/S0307-904X(01)00071-3.

[5] S. Ghosh, K. Chaudhuri, and Optimization, "An order-level inventory model for a deteriorating item with Weibull distribution deterioration, time-quadratic 
demand and shortages," Advanced Modeling, vol. 6, pp. 21-35, 2004. https://camo.ici.ro/journal/vol6/v6a2.

[6] S. Ghosh and K. Chaudhuri, "An EOQ model with a quadratic demand, timeproportional deterioration and shortages in all cycles," International Journal of Systems Science, vol. 37, pp. 663-672, 2006. https://doi.org/10.1080/00207720600568145.

[7] A. Roy, "An inventory model for deteriorating items with price dependent demand and time varying holding cost," Advanced modeling optimization, vol. 10, pp. 2537, 2008. https://camo.ici.ro/journal/vol10/v10a2.

[8] M. Cheng and G. Wang, "A note on the inventory model for deteriorating items with trapezoidal type demand rate," Computers Industrial Engineering, vol. 56, pp. 1296-1300, 2009. https://doi.org/10.1016/j.cie.2008.07.020.

[9] C. K. Jaggi and P. Verma, "Two-warehouse inventory model for deteriorating items with linear trend in demand and shortages under inflationary conditions," International Journal of Procurement Management, vol. 3, p. 54, 2010. https://doi.org/10.1504/IJPM.2010.029775.

[10] B. Mandal, "An EOQ inventory model for Weibull distributed deteriorating items under ramp type demand and shortages," Opsearch, vol. 47, pp. 158-165, 2010. https://doi.org/10.1007/s12597-010-0018-x.

[11] T. Roy and K. Chaudhuri, "A finite time horizon EOQ model with ramp-type demand rate under inflation and time-discounting," International Journal of Operational Research, vol. 11, pp. 100-118, 2011. https://doi.org/10.1504/IJOR.2011.04033.

[12] M. Cheng, B. Zhang, and G. Wang, "Optimal policy for deteriorating items with trapezoidal type demand and partial backlogging," Applied Mathematical Modelling, $\quad$ vol. $35, \quad$ pp. $3552-3560, \quad 2011$. https://doi.org/10.1016/j.apm.2011.01.001.

[13] N. Kumar, S. R. Singh, and R. Kumari, "An inventory model with time-dependent demand and limited storage facility under inflation," Advances in Operations Research, vol. 2012, 2012. http://dx.doi.org/10.1155/2012/321471.

[14] T. Sarkar, S. Ghosh, and K. Chaudhuri, "An optimal inventory replenishment policy for a deteriorating item with time-quadratic demand and time-dependent partial backlogging with shortages in all cycles," Applied MathematicsComputation, vol. 218, pp. 9147-9155, 2012. https://doi.org/10.1016/j.amc.2012.02.072.

[15] V. K. Mishra, L. S. Singh, and R. Kumar, "An inventory model for deteriorating items with time-dependent demand and time-varying holding cost under partial backlogging," Journal of Industrial Engineering International, vol. 9, p. 4, 2013. https://doi.org/10.1186/2251-712X-9-4.

[16] S. K. De and S. S. Sana, "An EOQ model with backlogging," International Journal of Management Science Engineering Management, vol. 11, pp. 143-154, 2016. https://doi.org/10.1080/17509653.2014.995736.

[17] P. Manna, S. K. Manna, and B. C. Giri, "Economic Order Quantity Model with Ramp Type Demand Rate, Constant Deterioration Rate and Unit Production Cost," Yugoslav Journal of Operations Research, vol. 26, 2016. http://www.yujor.fon.bg.ac.rs/index.php/yujor/article/view/8.

[18] M. E. Islam, S. I. Ukil, and M. S. Uddin, "A time dependent inventory model for exponential demand rate with constant production where shelf-life of the product is finite," Open Journal of Applied Sciences, vol. 6, p. 38, 2016. https://doi.org//10.4236/ojapps.2016.61005. 
[19] N. K. Kaliraman, R. Ritu, S. Chandra, and H. Chaudhary, "Two warehouse inventory model for deteriorating item with exponential demand rate and permissible delay in payment," Yugoslav Journal of Operations Research, vol. 27, pp. 109-124, 2016. http://yujor.fon.bg.ac.rs/index.php/yujor/article/view/22/16.

[20] R. Tripathi, S. Pareek, and M. Kaur, "Inventory model with exponential timedependent demand rate, variable deterioration, shortages and production cost," International Journal of Applied Computational Mathematics, vol. 3, pp. 14071419, 2017. https://doi.org/10.1007/s40819-016-0185-4.

[21] S. Singh, S. Singh, and S. Sharma, "A partially backlogged EPQ model with demand dependent production and non-instantaneous deterioration," International Journal of Mathematics in Operational Research, vol. 10, pp. 211228, 2017. https://doi.org/10.1504/IJMOR.2017.081926. 